\title{
Knowledge creation, business and art: exploring the contradictions and commonalities
}

Yassaman Imani University of Hertfordshire

\begin{abstract}
For over a decade, knowledge management (KM), a strand of strategic management, has studied the nature and role of knowledge in social groupings such as modern organizations. The result is a significant pool of insights, some useful, a few rhetorical, simplistic and shallow. This article examines four knowledge creation theories in KM and illustrates how some of the insights useful in business contexts could apply to the creative and practice-led disciplines (CPD), especially the arts and design. At first sight, the gap between these disciplines seems wide. However, they share many commonalities and interests, as strategic management field is also multi-disciplinary, practice-based and regards creativity as imperative. This article illustrates that KM could provide valuable insights on issues such as the processes of knowledge creation in complex contexts, and CPD could also inform strategic and KM discourse by offering unique approaches for tapping into, and vivid explications of communicating, tacit knowledge at individual or group level. Demonstrating these insights' potential value beyond the boundaries of their original disciplines indicates some degree of transdisciplinary significance, which will hopefully stimulate further thoughts and more in-depth studies amongst scholars of both camps.
\end{abstract}




\section{Keywords}

arts

design

knowledge creation

knowledge management

tacit knowledge

\section{Background}

The ambiguous nature of knowledge, a lack of consensus on its definition, and the highly divergent and multidisciplinary nature of the knowledge management (KM) contributions have resulted in many contrasting and/or complementary perspectives on the same phenomena, which makes KM discourse highly fragmented. Recently, however, KM has been re-examining some of its own assumptions. In particular, its most influential theory, the knowledge conversion theory (Nonaka and Konno 1998; Nonaka and Takeuchi 1995; Nonaka, Toyama and Konno 2000), which draws on Polanyi (1962, 1969), has been criticized for its misunderstanding of Polanyi (Ray and Clegg 2005; Tsoukas 2003), its empirical rigour (Gourlay 2004, 2006a, 2006b; Gourlay and Nurse 2005), and by implication, its practical value. At the same time, an increasing number of organizations have set up and practice KM. These academic re-evaluations and practical applications signify that KM is conceptually and practically stronger. 
In the creative and practice-led disciplines (CPD) camp, knowledge has also been the focus of academic inquiry. Concepts such as experiential learning and tacit knowledge (e.g. Bowman 1982; Hobgood 1970; Luck 2003; Sorri 1994), and the challenges and possibilities of defining and communicating knowledge in arts and design have been studied (Ahmed 2005; Broens and de Vries 2003; Niedderer 2007; Rust 2004; Stempfle and Badke-Schaub 2002), mainly at individual and group level. There are some overlaps however, each camp offers unique insights as well. Moving beyond the contradictions and limitations of KM, this article examines some debates in $\mathrm{CPD}$ and four knowledge creation theories in $\mathrm{KM}$ in order to identify similar and unique insights in each camp, and illustrate their potential value beyond their original disciplines.

The rest of the article is structured as follows. It starts by a brief background on knowledge creation models. It then examines aspects of Polanyi's theory central to this debate. Next, it examines some CPD studies, especially in arts and design. Afterwards, it investigates the possible application of four knowledge creation theories in CPD research and practice. Finally, it discusses the main contributions and limitations of this research, and highlights some opportunities for further research.

\section{Knowledge creation theories}

Knowledge creation theories provide contrasting, competing and/or complementary perspectives on the processes of knowledge creation in social contexts such as groups and organizations. There are numerous such theories, however, four theories have been chosen that provide relevant complementary and competing insights. They are 'knowledge conversion model' (Nonaka 1991; Nonaka and Konno 1998; Nonaka and Takeuchi 1995; Nonaka, Toyama and Konno 2000), 'communities of practice' (Brown 
and Duguid 1991, 2001; Lave and Wenger 1991; Wenger 1998, 2000), 'knowledge integration theory' (Grant 1996a, 1996b) and 'complex responsive processes of relating' (Stacey 2001, 2003).

Knowledge management debates generally agree that unlike data and information, knowledge is context-specific and essentially related to human actions (e.g. Boisot 1998; Choo 1998; Davenport and Prusak 1998; Nonaka and Konno 1998; Nonaka and Takeuchi 1995; Sanchez 2003; Von Krogh, Ichijo and Nonaka 2000). Most KM debates also draw on Polanyi's (1966) distinction between tacit and explicit knowledge and assume that knowledge exists at individual, group and organizational level (for an exception see, Stacey 2001, 2003). However, Polanyi's prominence in KM is due to Nonaka's theory (it draws on it), which in turn, has inspired a great number of other scholars (e.g. Boisot 1998; Choo 2002; Conner and Prahalad 1996; Davenport and Prusak 1998; Dixon 2000; Grant 1996a; Nahapiet and Ghoshal 1998; Spender 1996; Von Krogh, Ichijo and Nonaka 2000). This theory's influence has been to such an extent that some scholars draw on Nonaka's work on tacit and explicit dimensions of knowledge without referring to Polanyi (Rynes, Bartunek and Daft 2001; Yolles 2000).

\section{The Polanyi effect}

Michael Polanyi's $(1958,1962,1966,1969)$ theory of knowledge and knowing has been discussed extensively both in KM (Gourlay 2004; Nonaka and Takeuchi 1995; Nonaka, Toyama and Konno 2000; Ray and Clegg 2005; Tsoukas 2003) and in the arts and design literature (e.g. Niedderer 2007; Rust 2004; Sorri 1994). However, a few points merit further elaboration. First, Polanyi problematizes the duality of mind and body, a concept introduced by Plato (who assumed that knowing and judgments taking place in the mind, acting through the body), and argues that human cognition, to some extent, is 
bodily in nature. Second, he criticizes the scientific community's pretence to create pure objective knowledge (Polanyi 1969: 195):

The ideal of a strictly explicit knowledge is indeed self-contradictory; deprived of their tacit coefficients, all spoken words, all formulae, all maps and graphs are strictly meaningless.... The false ideal of a strictly explicit knowledge was pursued with the greatest zeal in the twentieth century by modern positivism.

Third, he initially referred to tacit knowledge as a process of knowing (Polanyi 1962), but later expanded it arguing that 'it was possible to "know" parts explicitly' (cited in Gourlay 2004: 92). Nonaka and his colleagues have magnified this. Nonetheless, accepting Polanyi's account that aspects of tacit knowledge (potentially) could be verbalized has major practical implications for KM and CPD, for it suggests that if parts of tacit knowledge could be articulated, then they could be shared, transferred and reused in different or similar contexts.

Polanyi provides a thorough explication for the process of 'knowing' (knowledge creation) at individual level. However, his account is ambiguous and open to multiple interpretations (Hedlund 1994), and as Polanyi's thoughts on the subject evolved, the interpretations have multiplied depending on which publication one read. In addition, if one problematizes the primacy of individual to group (social), as it has been the case in CPD (e.g. Coyne and Snodgrass 1995) and in strategy (Stacey 2001, 2003), then Polanyi's theory fails to explain how knowledge and shared meaning are created in complex social groupings such as large communities of experts or organizations. Finally, mindful of these limitations, some scholars (including Nonaka) have extended the theory in different ways to serve their own purposes (a usual practice 
in social sciences). Some scholars suggest new meanings or subsets to the existing dimensions of knowledge (Choo 2002; Conner and Prahalad 1996; Hedlund 1994; Nonaka 1991; Nonaka and Takeuchi 1995), others add or try to better define the ontological levels of knowledge (Cook and Brown 1999; Nahapiet and Ghoshal 1998; Spender 1996). For example, Spender combines tacit-explicit (dimensions of knowledge) with individual and social knowledge (ontological levels of knowledge) and creates a $2 \times 2$ matrix.

To sum up, KM scholars, generally, have adopted a rather simplistic (some may suggest, pragmatic) interpretation of Polanyi, and several scholars adapted it for their own purposes. The next part is a focused review of some CPD debates on knowledge.

\section{Knowledge creation in CPD}

Knowledge has been studied in the arts and design literature from different perspectives. For example, some scholars aim to 'classify' or 'index' knowledge for different purposes (Ahmed 2005; Broens and de Vries 2003; Niedderer 2007), others draw on Polanyi's theory (Polanyi 1962, 1966, 1969) to describe knowledge creation at individual (e.g. Sorri 2004) and group level (e.g. Rust 2004).

Coyne and Snodgrass (1995) examine how different schools of thought ('domain of discourse'), namely rationalism, romanticism, pluralism and postrationalism use different metaphors to define and resolve problems in design inquiry. The similarities to management discourse, noted by the authors, are remarkable, as for example, the methods recommended in rationalism mirror strategic planning process. However, for the purpose of this article, the focus remains on the rationalism and post- 
rationalism part of their study, which provides useful pointers to classify the debates of both camps.

Rationalism, according to Coyne and Snodgrass (1995), regards logic as a universal language. It uses many metaphors, a dominant one being 'design process as a system'. These metaphors generally 'embrace certain oppositions such as chaos and order, interior and exterior, mind and matter, and subject and object' (pp. 40-41). Systematization is also a major feature of rationalistic approach, which advocates creating 'lists, charts, tables, and diagrams to identify goals, criteria and plans' (p. 51). Coyne and Snodgrass argue that these tools have their own value but cannot capture human knowledge. Rationalism also believes in the primacy of the individual, which means that knowledge 'has internal residence in the individual', and its communication requires the externalization of thought (p. 53). In other words, knowledge has to be made explicit and captured (in different media). However, Coyne and Snodgrass say, 'Explicating knowledge is a pseudoproblem. It only exists as a problem if we think that knowledge is propositional and logical' (p. 58). Moreover, in their view, 'there are never enough rules or procedures to capture even the simplest domain of human expertise' (p. 57).

In post-rationalism, the definitions of problems change. The emphasis is on 'design as a collaborative enterprise'. 'Post-rationalism is an impermanent set of metaphors, characterized by instability' (p. 59). In this school of thought, reflection and dialogue create understanding and knowledge in research and practice, and dichotomies are rejected in favour of integration. Post-rationalism challenges (problematizes) individualism and seeks collaboration. Metaphors are not pre-given, they emerge in dialogue. 
It should be noted that aspects of both rationalism and post-rationalism could be observed in most cases of research and practice (in design and strategic management). Let us examine some debates against the hallmarks of rationalism and post-rationalism. In her eloquent account on ceramic making, Sorri (1994) describes the process of tacit knowing (Polanyi 1962) at 'individual level', which validates Polanyi's debate against the duality of body and mind. Critical of a separation between making and thinking, Sorri argues that making is also a cognitive activity. Since tacit knowing is acquired through practice and it could only be demonstrated, no explicit criteria apply to its measurement or evaluations. Therefore, Sorri argues that it is (or should be) up to the experts of the field to agree on some 'open-ended and flexible' criteria (ibid.). However, she observes that articulating tacit knowing tends to use metaphoric language, perhaps an indication of the limitations of conversational or written language.

Assuming that knowledge is either procedural or declarative, Broens and de Vries (2003) propose some classifications of technological knowledge in engineering design for a KM system (a database). In a similar study, Ahmed (2005) develops a method to index intuitive knowledge of engineering designers. In this study, however, information and knowledge are used interchangeably, as for example, indexed (explicit) knowledge is described as 'information' (p. 565). Both studies demonstrate aspects of rationalist and post-rationalist approaches. The overall approach to classify and capture knowledge is rationalistic, yet arriving at shared understanding through dialogue is postrationalist.

In another study, Rust (2004) adopts Polanyi's (1958) notion of 'illumination' to describe the processes of knowledge creation at 'group level' in a number of 
multidisciplinary projects where scientists and designers worked together. In a sense, he explicates knowledge 'integration' processes in some multidisciplinary inquiries. Rust demonstrates that by producing experimental artifacts designers introduce a 'creative dimension' to 'scientific enquiry' (p. 78), which could prompt scientists to use their tacit knowledge for creating new ideas. Rust elaborates (p. 81):

While Polanyi probably is correct to say that simple languages with abstract, generalpurpose symbols are necessary for the development of knowledge, there still is a place for rich, complex, literal representation.

Sorri (1994) argues that 'metaphoric language' seems useful for articulation of tacit knowing, a theme discussed in KM (Nonaka and Takeuchi 1995). Rust (2004) makes a persuasive case for using 'artifacts' as a means of tapping into, and communicating, tacit knowledge. His debate offers new insights to the KM discourse.

Luck's (2003) study of participatory design (design as a social process) provides the final example for the post-rationalistic approach. Her study demonstrates how the architect-user interactions could result in articulating aspects of 'tacit knowledge' and creating shared understandings (knowledge).

In summary, the CPD studies on knowledge, especially in arts and design, provide vivid examples of knowledge creation at individual and group level. Most assumptions and results are similar to KM debates, with the exception of Rust's (2004) debate, which informs KM literature. The next part examines four knowledge creation theories and illustrates their relevance to CPD and starts with the knowledge conversion theory. 


\section{Knowledge conversion theory}

The knowledge conversion theory or the SECI model (Nonaka and Takeuchi 1995; Nonaka and Konno 1998;Nonaka, Toyama and Konno 2000) explains how Japanese companies tap into their employees' tacit knowledge to create innovative products and processes. By drawing on Polanyi $(1962,1966)$ and a number of studies of innovation in some Japanese firms, this theory suggests that new knowledge is created through interactions between tacit and explicit knowledge as they convert into each other. The SECI model is a matrix comprising four outcomes of knowledge conversion:

- Socialization - tacit to tacit, e.g. traditional apprenticeship

- Externalization - tacit to explicit, e.g. concept creation in new product development

- Combination - explicit to explicit, e.g. manuals

- Internalization - explicit to tacit, e.g. training programmes, reading manuals and so forth

Ontologically, knowledge is regarded as humanistic (unlike information), and originally exists at individual level but becomes social through interactions (Nonaka, Toyama and Konno 2000). $B a$, a Japanese word, is where and when (space and time) knowledge is created. Four types of $b a$ emerge in most organizations (ibid: 51-52):

- Originating - face-to-face interactions

- Dialoguing - collective face-to-face

- Exercising - individual virtual

- Systemizing - collective virtual 
The theory is based on a mixture of rationalist (primacy of individual) and postrationalist assumptions (socialization, dialoguing and so forth). The SECI model has been critiqued for its (mis)understanding of Polanyi (Gourlay 2006a, 2006b; Ray and Clegg, 2005; Tsoukas 2003), its unsound empirical foundations (Gourlay 2006b), and for being simplistic and embedded in the Japanese culture and management practices (Glisby and Holden 2003). However, business practitioners regard it as useful, and some have subscribed to it fully (e.g. Kikawada and Holtshouse 2001) or partially (Brand 1998). This theory, despite its limitations, provides useful clues on how tacit and explicit dimensions of knowledge interact, and what methods could facilitate knowledge-creation processes.

\section{Communities of practice}

Communities of practice (CoPs) have existed for centuries in tribes and craft guilds, basically, in arts and design. Recently, however, the concept of CoPs has been adopted to explain the dynamics of knowledge creation and sharing in social groupings such as organizations (Brown and Duguid 1991, 2001; Lave and Wenger 1991; Wenger 1998, 2000). CoPs are groups of people who share a concern, a set of problems or a passion about a topic. They have boundaries in terms of membership, and social interactions and learning is situated in social 'participation' processes (Wenger 1998). Membership is usually voluntary and self-selective, and members have self-responsibility (ibid.). Practice in the communities has three 'interdependent' and 'interlocked' dimensions (Brown and Duguid 1998: 96-97):

1. 'Mutual engagement' defines membership of community and could generate harmony, as well as tension and conflict. 
2. 'Joint enterprise' sets CoPs apart from social structures - where negotiations take place collectively and agreements and disagreements are part of the process.

3. 'Shared repertoire' is the collective medium (created by the history of CoPs), which members used to engage with each other and include language, ways of doing things, stories, symbols and so forth.

Knowledge flows within the community better than between different communities because of the members' common experiences and shared language (Newell et al. 2002). Hence, 'knowledge tends to stick at the boundaries of practice' because 'boundaries do not just keep knowledge in - they keep it out too' (ibid: 123). CoPs could provide support for work processes such as troubleshooting and/or dissemination of best practice (Orr 1990). It is also noted that 'the process of developing knowledge and the community are significantly interdependent: practice develops the understandings, which can reciprocally change the practice and extend the community' (Brown and Duguid 1998: 25). The guilds and other professional associations are examples of CoPs.

Some limitations have been associated with the concept of CoPs. For example, the diversity of members can cause problems, or CoPs can become arrogant, insular, inward-looking and over-controlling (Newell et al. 2002), adversely affecting the creation of new knowledge. More importantly, the concept of CoPs cannot explain how knowledge (shared understanding) is created amongst people with different knowledge bases. The knowledge integration theory (Grant 1996a), discussed next, could provide some useful insights to fill this gap. 


\section{The knowledge integration theory}

Not persuaded by the concept of knowledge conversion or transfer, Grant (1996a: 114) argues that social groupings such as organizations need efficient integration of knowledge because:

Transferring knowledge is not an efficient approach to integrating knowledge. If production requires the integration of many people's specialist knowledge, the key to efficiency is to achieve effective integration while minimizing knowledge transfer through cross-learning by organizational members.

Grant, rather skillfully or sensibly, refrains from defining knowledge beyond what he calls a tautology, 'that which is known' (p. 110), and associates knowing-how with tacit knowledge and knowing-what with explicit knowledge. The difference between these types of knowledge, according to Grant, 'lies in transferability and the mechanisms for transfer across individuals, across space, and across time' (p. 111). He regards knowledge as residing in individual minds and knowledge creation as an individual activity (a rationalist assumption), and identifies four mechanisms for knowledge integration (Grant 1996a, 2002):

1. Rules and directives - coordinate actions and could be useful for converting tacit knowledge into explicit

2. Sequencing - refers to the timing of knowledge integration where specialized knowledge can be used independently

3. Routines - without reliance on rules, routines can sustain complex interactions in groups and organizations 
4. Group problem-solving and decision-making - rely on interactions for solving novel and complex problems (e.g. a new design)

Broadly speaking, only the last mechanism fits in the post-rationalism approach. All these mechanisms work if enough common knowledge exists amongst group members, which include a common language, identification of the individuals' knowledge domain and some degree of commonality between the specialized knowledge of individuals (Grant 1996a, 2002). Grant provides a rather mechanistic explication of knowledge integration where the rationalist approach is more dominant. Rust's (2004) examples of designers working with natural scientists are more pertinent for describing the complex processes of knowledge integration.

Nonetheless, this theory provides an explanation on how people with different knowledge bases, skills and expertise work together and 'integrate' their knowledge for a purpose (new product development, research and so forth). My area of expertise is in strategy and knowledge management. If a design scholar and I decide to work together on a joint research project, although both of us will learn more about each other's area of expertise, our knowledge will not get 'converted' or 'transferred'. Rather, the research outcome will be the result of our integrated knowledge, or at least that is how Grant would describe it. A film production team, a construction project or an orchestra are examples of groups of people with diverse knowledge bases and skills who work to integrate their knowledge to produce a film, build an edifice or play a symphony. Therefore, this theory complements the concept of CoPs, suggests 'methods' for effective integration of knowledge (rationalist), but as Grant (1996a) admits himself, only focuses on knowledge integration and cannot explain how knowledge is created or 
applied in social groupings. The last theory, which belongs to the post-rationalist approach, could shed some light on these issues.

\section{Complex responsive processes of relating (CRP)}

Ralph Stacey's $(2001,2003)$ theory of complex responsive processes of relating (CRP) offers a new way of thinking. Stacey (2001: 95) argues that knowledge is created through interactions:

The individual mind/self is an interactive role-playing process conducted privately and silently in the medium of symbols by a body with itself and the group, organization and society are all also interactive processes in the medium of the same symbols, this time publicly and often vocally between different bodies. The individual and the social, in this scheme, simply refer to the degree of detail in which the whole process is being examined.

In Stacey's debate, which rejects systems thinking, individual mind arises continuously in the act of relating to other people. Stacey focuses on the micro level of interactions (local), and explains the whole picture with the help of complexity sciences and the notion of 'self-organizing entities'. Paying attention to local interactions is (or should be) the focus. The rest (the bigger picture) emerges in self-organizing fashion through pattern-creating interactions. Stacey (2001: 98) regards the notion of storing and retrieving knowledge redundant and says knowledge 'is not stored anywhere and then retrieved to form the basis of action', but reproduced through interactions. Hence, in his view, knowledge is a relational process which cannot be transmitted from one head to another.

CRP theory is distinctively unique and this review does not do it justice. However, it has some similarities with other KM debates. Like Nonaka, it draws on 
social constructionism (Stacey subscribes to some aspects of it) within the postrationalist paradigm. Stacey $(2001,2003)$ distinguishes between private and public (group) conversations. Nonaka assumes that knowledge is created through actions (individual) and interactions (social) (Nonaka, Toyama and Konno 2000). However, there are some major differences as well. First, ontologically, Nonaka puts knowledge at individual level, which then becomes social through interactions, but in Stacey's view, there is no divide between individual and social level. Second, in Nonaka's theory, knowledge is embedded in, and an outcome of, the processes. In CRP, there is no ontological divide between knowledge and the process, both are the same.

Polanyi's theory could explain how a designer uses knowledge and expertise to create a new artifact. CRP provides a framework to describe how a designer's knowledge and understanding evolves through interactions with others in or outside her discipline. For example, Niedderer (2007) highlights the challenges of communicating aspects of knowledge created by design research in a way that could be applied to practice or other research projects. If she decided to take her research further, then CRP would provide an appropriate perspective or framework to capture the process in which her understanding and knowledge evolve through her silent reflection, thinking and writing, and public conversations with others (practitioners, her academic colleagues in design or other disciplines, at her institution and beyond).

By shifting the focus to interactions, CRP can explain how knowledge is created in complex social settings, and provides some fresh insights for CPD. However, it relies on limited media of discourse, mainly language. Design scholars (for example, Rust, 2004) could expand it to include artifacts. 


\section{Conclusions}

The main aim of this article was to examine the possible relevance of four different theories of knowledge creation in $\mathrm{KM}$ to creative and practice-based disciplines, in particular to arts and design. It suggests that both camps have unique insights beneficial to the other discipline's research and practice. A review of CPD literature demonstrated a number of unique debates on creative methods for tapping into, and communicating, tacit knowledge. An interesting example is the use of artifacts (Rust 2004). This highly contentious area in KM literature could benefit from examples of articulating tacit knowledge. KM's focus on the nature and role of knowledge in social groupings such as large organizations has resulted in some novel findings that could be adopted (or adapted) for CPD. For example, complex responsive processes of relating theory (Stacey 2001) provides a practical framework for capturing the social nature of knowledge creation in complex contexts. These conclusions, however, should be considered in light of the limitations of this research, in which a small number of studies were examined from each camp. Moreover, my knowledge of the CPD discourse is very limited. Therefore, more studies are required to provide a better understanding of how these disciplines discuss knowledge creation, and demonstrate what methods could be used for tapping into, and communicating aspects of tacit knowledge amongst people

with the same or diverse knowledge and skills. In particular, CoPs and CRP could be better examined regarding their applications in the creative and practice-based disciplines.

\section{References}


Ahmed, S. (2005), 'Encouraging Reuse of Design Knowledge: A Method to Index Knowledge', Design Studies, 26, pp. 565-92.

Barry, D. and Elmes, M. (1997), 'Strategy Retold: Toward a Narrative View of Strategic Discourse', Academy of Management Review, 22: 2, pp. 429-52.

Blackler, F. (1995), 'Knowledge, Knowledge Work and the Organizations: An Overview and Interpretation', Organisation Studies, 16: 6, pp. 1021-46.

Boisot, M. (1998), Knowledge Assets: Securing Competitive Advantage in the Information Economy, Oxford: Oxford University Press.

Bowman, W. D. (1982), 'Polanyi and Instructional Method in Music', Journal of Aesthetic Education, 16: 2, pp. 75-86.

Brand, A. (1998), 'Knowledge Management and Innovation at 3M', Journal of Knowledge Management, 2: 1 (September), pp. 17-22.

Broens, R. and de Vries, M. (2003), 'Classifying Technological Knowledge for Presentation to Mechanical Engineering Designers', Design Studies, 24, pp. 457-71.

Brown, J. S. and Duguid, P. (1991), 'Organizational Learning and Communities of Practice: Toward a Unified View of Working, Learning and Innovation', Organization Science, 2: 1 , pp. $40-57$.

(1998), 'Organizing Knowledge', California Management Review, 40(3),

Spring, 90-111.

(2001), 'Structure and Spontaneity: Knowledge and Organization', in I.

Nonaka and D. Teece (eds), Managing Industrial Knowledge: Creation, Transfer and Utilization, London: Sage, pp. 44-67.

Choo, C. W. (1998), The Knowing Organization: How Organizations Use Information to Construct Meaning, Create Knowledge, and Make Decisions, New York: Oxford University Press. (2002), 'Sensemaking, Knowledge Creation, and Decision Making: Organizational Knowing as Emergent Strategy', in C. W. Choo and N. Bontis (eds), The Strategic 
Management of Intellectual Capital and Organizational Knowledge, Oxford: Oxford University Press, pp. $79-88$.

Conner, K. R. and Prahalad, C. K. (1996), 'A Resource-based Theory of the Firm: Knowledge vs. Opportunism', Organization Science, 7, pp. 477-501.

Cook, S. D. N. and Brown, J. S. (1999), 'Bridging Epistemologies: The Generative Dance between Organizational Knowledge and Organizational Knowing', in S. Little, P. Quintas and R. Ray (eds), Managing Knowledge: An Essential Reader, London: Sage Publications, pp. 68-101.

Coyne, R. and Snodgrass, A. (1995), 'Problem Setting within Prevalent Metaphors of Design', Design Issues, 11: 2, pp. 31-61.

Davenport, T. H. and Prusak, L. (1998), Working Knowledge: How Organizations Manage What They Know, Cambridge, MA: Harvard Business School Press.

Dixon, N. (2000), Common Knowledge: How Companies Thrive by Sharing What They Know, Boston, MA: Harvard Business School Press.

Glisby, M. and Holden, N. (2003), 'Contextual Constraints in Knowledge Management Theory: The Cultural Embeddedness of Nonaka's Knowledge-Creating Company', Knowledge and Process Management, 10: 1, pp. 29-36.

Gourlay, S. (2004), 'Knowing as Semiosis: Steps towards a Reconceptualization of "Tacit Knowledge", , in H. Tsoukas and N. Mylonoplous (eds), Organizing as Knowledge Systems: Learning, Knowledge, and Dynamic Capabilities, Basingstoke: Palgrave McMillan, pp. 86-105.

(2006a), 'Towards Conceptual Clarity for "Tacit Knowledge”: A Review of Empirical Studies', Knowledge Management Research and Practice, 4, pp. 60-69. (2006b), 'Conceptualizing Knowledge Creation: A Critique of Nonaka's Theory', Journal of Management Studies, 43: 7, pp. 1415-36.

Gourlay, S. and Nurse, A. (2005), 'Flaws in the "Engine" of Knowledge Creation: Nonaka's SECI Model', in A. F. Buono and F. Poutfelt (eds), Challenges and Issues in 
Knowledge Management, (Research in Management Consulting), vol. 5, Greenwich: Connecticut, Information Age Publishing, pp. 293-315.

Grant, R. M. (1996a), 'Toward a Knowledge-based Theory of the Firm', Strategic Management Journal, 17: Special Winter issue, pp. 109-122.

(1996b), 'Prospering in Dynamically Competitive Environments: Organizational Capability as Knowledge Integration', Organization Science, 3, pp. 375-87. (2002), 'The Knowledge-based View of the Firm', in C. W. Choo and N. Bontis (eds), The Strategic Management of Intellectual Capital and Organizational Knowledge, Oxford: Oxford University Press, pp. 133-48.

Hedlund, G. (1994), 'A Model of Knowledge Management and the N-Form Corporation', Strategic Management Journal, 15, pp. 73-90.

Hobgood, B. M. (1970), 'The Concept of Experiential Learning in the Arts', Educational Theatre Journal, 22: 1, pp. 43-52.

Kikawada, K. and Holtshouse, D. (2001), 'The Knowledge Perspective in the Xerox Group', in I. Nonaka and D. Teece (eds), Managing Industrial Knowledge: Creation, Transfer and Utilization, London: Sage Publications.

Lave, J. and Wenger, E. (1991), Situated Learning: Legitimate Peripheral Participation, New York: Cambridge University Press.

Leonard, D. and Sensiper, S. (1998), 'The Role of Tacit Knowledge in Group Innovation', Organization Science, 5: 1, pp. 14-37.

Luck, R. (2003), ‘Dialogue in Participatory Design’, Design Studies, 24, pp. 523-35.

Nahapiet, J. and Ghoshal, S. (1998), 'Social Capital, Intellectual Capital, and the Organizational Advantage', Academy of Management Review, 23: 2, pp. 242-66.

Newell, S., Robertson, M., Scarborough, H. and Swan, J. (2002), Managing Knowledge Work, Basingstoke: Palgrave.

Niedderer, K. (2007), 'Mapping the Meaning of Knowledge in Design Research', Design Inquiries (forthcoming). no

Nonaka, I. (1991), The Knowledge Creating Company, Harvard Business Review, 
69(6), 96-104.

Nonaka, I. and Konno, N. (1998), 'The Concept of Ba: Building a Foundation for Knowledge Creation', California Management Review Spring, 40: 3, pp. 1-15. and Takeuchi, H. (1995), 'The Knowledge Creating Company', New York: Oxford University Press.

Toyama, R. and Konno, N. (2000), 'SECI, Ba, and Leadership: A Unified Model of Dynamic Knowledge Creation', Long Range Planning, 33: 1, pp. 5-34.

Orr, J. E. (1990), ‘Sharing Knowledge, Celebrating Identity: Community Memory in a Service Culture', in D. Middleton and D. Edwards (eds), Collective Remembering, London: Sage, pp. 169-89.

Polanyi, M. (1958), Personal Knowledge: Towards a Post-Critical Philosophy, London: Routledge and Kegan Paul.

(1962), Personal Knowledge: Towards a Post-Critical Philosophy, Chicago: University of Chicago Press.

(1966), The Tacit Dimension, London: Routledge and Kegan Paul.

(1969), in M. Greene (ed.), Knowing and Being: Essays by Michael Polanyi, Chicago,

IL: University of Chicago Press.

Ray, T. and Clegg, S. (2005), 'Tacit Knowing, Communication and Power: Lessons from Japan', in S. Little and T. Ray (eds), Managing Knowledge: An Essential Reader, London: Sage Publications, pp. 319-49.

Rust, C. (2004), 'Design Enquiry: Tacit Knowledge and Innovation in Science', Design Issues, 20: 4, pp. 76-85.

Rynes, S. L., Bartunek, J. M., and Daft, R. L. (2001), 'Across the Great Divide: Knowledge Creation and Transfer between Practitioners and Academics', Academy of Management Journal, 44: 2, pp. 340-57.

Sanchez, R. (2003), 'Managing Knowledge into Competence: The Five Learning Cycles of the Competent Organization', in R. Sanchez (ed.), Knowledge Management and Organizational Competence, Oxford: Oxford University Press, pp. 3-37. 
Sorri, M. (1994), 'The Body Has Reasons: Tacit Knowledge in Thinking and Making', Journal of Aesthetic Education, 28: 2, pp. 15-26.

Spender, J. C. (1996), 'Managing Knowledge: The Basis of a Dynamic Theory of the Firm', Strategic Management Journal, 17: S2, pp. 45-62.

Stacey, R. D. (2001), Complex Responsive Processes in Organizations: Learning and Knowledge Creation, London: Routledge. (2003), Strategic Management and Organizational Dynamics: The Challenge of Complexity, 3rd edn, London: FT Prentice Hall.

Stempfle, J. and Badke-Schaub, P. (2002), 'Thinking In Design Teams: An Analysis of Team Communication’, Design Studies, 23: 5, pp. 473-96.

Tsoukas, H. (2003), 'Do We Really Understand Tacit Knowledge?' in M. Easterby-Smith and M. Lyles (eds), The Blackwell Handbook of Organizational Learning and Knowledge Management, Oxford: Blackwell, pp. 410-27.

Von Hippel, E. (1994), 'Sticky Information and the Locus of Problem-solving: Implications for Innovation', Management Science, 40, pp. 429-39.

Von Krogh, G., Ichijo, K. and Nonaka, I. (2000), Enabling Knowledge Creation, Oxford: Oxford University Press.

Wenger, E. (1998), Communities of Practice, Cambridge: Cambridge University Press. (2000), 'Communities of Practice and Social Learning Systems', Organization, 7: 2, pp. 225-46.

Yolles, M. (2000), 'Organizations, Complexity, and Viable Knowledge Management', Kybernetics, 29: 9/10, pp. 1202-22.

\section{Suggested citation:}

Imani, Y. (2007), 'Knowledge creation, business and art: exploring the contradictions and commonalities', Journal of Visual Art Practice, 6: 2, pp. xx-xx, doi: .

\section{Contributor details}


Yassaman Imani is a senior lecturer and Head of the Strategy Group at University of Hertfordshire, Business School. She lectures on strategy and knowledge management and has published on organizational culture and knowledge management. Her current research interests include managerial perceptions of learning and knowledge sharing in organizations, assessing the suitability of methodologies developed in other disciplines for adoption in strategic management research, systematic reviews in qualitative research and the academic-practice divide in strategic management. Her consultancy interests include strategic knowledge management, organizational change and developing knowledge-based strategies in organizations. Contact: Business School, University of Hertfordshire, College Lane, Hatfield, Herts. AL10-9AB, England.

Tel: 00441707285443

Fax: 00441707285455

E-mail: y.imani@herts.ac.uk 